\title{
Traffic safety and city structure: lessons for the future
}

\author{
Dinesh Mohan, $\mathrm{PhD}^{(1)}$
}

\section{Mohan D. \\ Traffic safety and city structure: lessons for the future. Salud Publica Mex 2008;50 suppl I:S93-SI00.}

\begin{abstract}
Objective. To understand the critical factors that are likely to influence road traffic fatality rates in large cities around the world in the next few decades. Material and Methods. Road traffic fatality data for 56 cities around the world and for cities with a population of greater than 100000 in the USA were collected and analysed to understand factors affecting differences in fatality rates. Results. There are wide variations in fatality rates across income levels and within similar incomes levels. The risk varies by a factor of about 20 between the best and the worst cities. Conclusions. These patterns appear to indicate that it is not enough to have the safest vehicle and road technology to ensure low road traffic fatality rates. City structure, modal share split, and exposure of motorists and pedestrians may have a significant role in determining fatality rates, in addition to enforcement, vehicle crashworthiness and road design.
\end{abstract}

Keywords: traffic safety; urban structure; sustainability

\author{
Mohan D. \\ Seguridad en el tránsito y estructura urbana: \\ lecciones para el futuro.
}

Salud Publica Mex 2008;50 supl I:S93-SI00.

\section{Resumen}

Objetivo. Entender los factores críticos con probabilidad de influir en las tasas de fatalidad por tránsito en las grandes ciudades del mundo durante las próximas décadas. Material y métodos. Se recolectaron y analizaron datos de fatalidad por tránsito de 56 ciudades del mundo y de las ciudades en Estados Unidos con más de 100000 habitantes para entender aquellos factores que determinan diferencias en las tasas de fatalidad. Resultados. Hay grandes variaciones en las tasas de fatalidad entre diferentes niveles de ingreso y dentro de niveles de ingreso similares. El riesgo varía por un factor de alrededor de 20 entre las mejores y las peores ciudades. Conclusión. Estos patrones parecen indicar que no es suficiente tener vehículos y tecnologías viales más seguros para asegurar tasas bajas de fatalidad por tránsito. La estructura de la ciudad, el reparto modal del transporte y la exposición de los automovilistas y peatones pueden tener un papel significativo en la determinación de las tasas de fatalidad, además de la aplicación de los reglamentos, la protección de los vehículos contra impacto y el diseño de las vialidades.

Palabras clave: seguridad del tránsito; estructura urbana; sostenible
$\mathrm{T}_{\mathrm{i}}^{\mathrm{h}}$ he global burden of disease due to road traffic injuries is expected to move from ninth position in 1990 to third position in 2020. This is mainly due to an increasing incidence of road traffic crashes in low and middle-income countries (LMIC). In most less-motorised countries, deaths due to road traffic injuries are between the second to sixth leading causes of death in the age groups 5 to 60 years. While the broader effects of road traffic injuries are experienced in rich as well as poor countries, total number of fatalities has shown a declining trend in many rich countries over the past two decades. On the other hand, deaths due to road

(I) Indian Institute of Technology Delhi. India.

Received on: July 19,2007 - Accepted on: November 9, 2007

Address reprint requests to: PhD. Dinesh Mohan. Transportation Research and Injury Prevention Programme. Indian Institute of Technology Delhi. Room 808, 7 floor, Main Building Hauz Khas, Mew Delhi I I00I6, India

E-mail:dmohan@cbme.iitd.ernet, in.trippdelhi@hotmail.com 
traffic injuries are still increasing in most of the less motorised countries ${ }^{1}$.

In LMIC, the vulnerable road users -pedestrians, bicyclists and motorised two-wheeler riders-, sustain a vast majority of the fatalities and injuries due to road traffic crashes. ${ }^{2}$ These countries are also experiencing higher rates of motorisation with an increase in incomes as compared to high-income countries (HIC); the latter are closer to a steady-state situation because of very high levels of vehicle ownership. The point to be noted is that most HIC have per capita incomes in excess of USD 20000 per year, whereas most LMIC have per capita incomes less than USD 10000 per year. These LMIC also constitute more than two-thirds of the world population. Therefore, we can very safely assume that (LMIC) will not become highly motorised societies in the next two decades or so. Consequently, vulnerable road users will remain the main victims of road traffic injuries for some time to come.

In the last three decades, the incidence of traffic crash fatalities and injuries has been reduced significantly in the HIC. This has been possible because of a careful analysis and evaluation of the factors associated with crashes and an implementation of policies resulting from the same. However, most of these policies are tailored to the specific situations and problems in those countries. The standards instituted for vehicles, roads and highway furniture are based on the traffic patterns and types of crashes that are more prevalent in those societies. On the other hand, virtually no less-motorised country has been successful in reducing the number of lives lost and people injured due to road traffic crashes in the last two decades. This is a curious situation as societies in all the less-motorised countries have been seriously concerned with the significant loss of lives due to road crashes for more than a decade. One cannot attribute this failure to forms of government, culture or religious practices in more than one hundred lessmotorised countries. Among these countries there is a great variation in size (populations can vary from less than one million to more than one billion), religion, cultural practices and forms of government. If these factors had a determining influence then there should have been a few less-motorised countries where road safety policies were successful. The fact that this has not happened means that there must be other reasons why the road safety situation in the LMIC is less than desirable.

\section{Material and Methods}

Road traffic fatality data were collected for 56 cities around the world for the period 2000 to 2003 from the following sources: official internet sites of respective cities/nations, journal publications in the same period and official city traffic and accident reports. In addition, data from the USA for all cities with populations above 100000 persons has also been used for analysis. An attempt was made to obtain data for cities representing a wide spectrum of per capita incomes -from the lowest to the highest income cities.

Road user deaths per million population has been used as the index of the probability of an individual dying due to an road traffic injury (RTI) in each city. This study attempts to look at trends and the health risk of individuals over a life span. Therefore, other indices like deaths per 10000 vehicles or deaths per passenger $\mathrm{km}$ have not been used, as these do not give an indication of road traffic injuries as a health problem. ${ }^{3}$ Since the number of trips taken in a city are proportional to its population, this index also proportional to the risk of fatality per trip for that city. This is the risk that individual road users must minimize if they have to maximize their life spans. The risk per trip is the experience that individuals approximate internally for decision-making regarding mode choice. ${ }^{4}$

We have not differentiated data sets for different countries by definitions of death based on time elapsed after the crash. This is because research studies show that 65 to $75 \%$ of fatal crash victims die before reaching the hospital in most countries, LMIC or HIC. ${ }^{1 ; 5}$ Therefore, the error introduced by not accounting for time of death will generally not exceed thirty percent, whereas the difference between different RTI rates between different countries and cities can exceed three hundred percent. ${ }^{6}$ Fatalities per unit population have been plotted against the per capita income in US dollars to examine the general influence of the economy in determining the average risk of an individual dying due to an RTI in each city. In the graph, a code for each city is used to provide a unique identifier

\section{Results and Discussion}

\section{Cities and their road safety experience}

Figure 1 shows road traffic fatalities per million population for a number of cities around the world. These data show that there are wide variations across income levels and within similar incomes levels. The risk varies by a factor of about 20 between the best and the worst cities. Some characteristics are summarised below:

- The highest fatality rates seem to be experienced by cities in the mid-income range of USD 2000 to 10000 per person per year. 


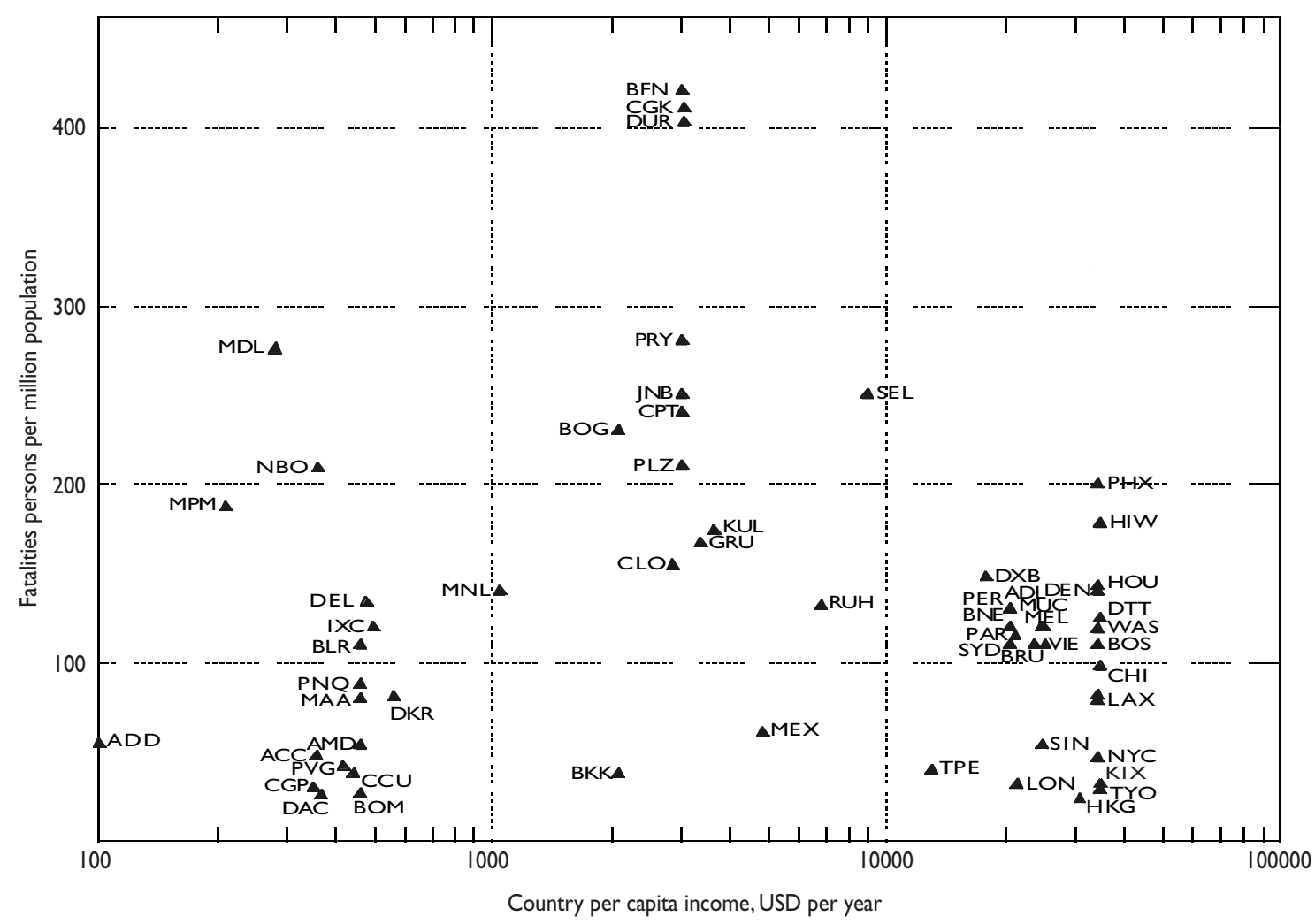

Figure I. FATALITY RISK FOR TRAFFIC CRASHES BY CITY - CITY CODES GIVEN IN APPENDIX I)

- Overall fatality risk in cities with very low per-capita incomes (less than USD 1000 ) and those with high incomes (greater than USD 10000 ) seems to be similar.

- There is a great deal of variation even in those cities where the per capita income is greater than USD 20000 per year.

These patterns appear to indicate that it is not enough to have the safest vehicle technology in HIC to ensure low road traffic fatality rates uniformly across cities in those locations. Even in very LMIC, the absence of funds and possibly unsafe roads and vehicles does not mean that all cities have high overall fatality rates. Provision of safely designed roads and modern, safe vehicles may be a necessary condition for low road fatality rates in cities, but not a sufficient one. The fact that there are wide variations for overall fatality rates among high income cities, where availability of funds, expertise and technologies are similar, indicates that other factors like land use patterns and exposure (distance traveled per day, presence of pedestrians, etc.) play a very important role also. This is probably why many European cities tend to have lower rates than those in the USA.

Vehicle speed is very strongly related to both the probability of a crash and the severity of injury -a $1 \%$ increase in average speeds can result in a 3 to $4 \%$ increase in fatalities. ${ }^{1}$ This may be the reason why some cities in middle-income countries have high fatality rates, because they have higher vehicle ownership than low income countries and roads encourage unsafe speeds without adequate attention being given to road safety. Similarly, cities that are considered to have greater traffic congestion (hence lower speeds) have higher rates than those with less congestion, though their incomes may be similar; Mumbai (BOM) in India with higher congestion has lower rates than Delhi (DEL) in India with lower congestion levels, and New York (NYC) in the USA has a lower rate than Houston (HOU), also in the USA.

The discussion above indicates that RTI fatality rates do not depend upon road and vehicle design alone and may also depend on exposure, incomes and traffic management and policing, which in turn also depend on societal income levels. To eliminate the issue of income 
we decided to examine the experience of cities within the USA. We have selected USA because researchers there generate the largest amount of scientific information on road safety and the society is not much worse off than any other in the availability of funds for road safety. Figure 2 shows pedestrian and motor vehicle fatality rates per 100000 population in 245 cities (population $>100000$ persons) in the United States of America. ${ }^{7}$ Table I shows 10 cities that have zero pedestrian deaths, of which eight also have no motor vehicle deaths. All these cities have populations between 100000 and 200 000. This is in contrast with 13 cities in the same population range which have some of the highest rates in the country (Table II).

It is clear that in US cities, size is not a determining factor in pedestrian or motor vehicle fatality rates. However, it is interesting that New York, which is the largest city in the US, has much lower vehicle and pedestrian crash rates than most cities in the country. If we take the five largest cities in the country -Philadelphia PA, Houston TX, Chicago IL, Los Angeles CA, and New York NY- we find that all of them have relatively low pedestrian fatality rates, but except New York, the others have high motor vehicle fatality rates. For motor vehicle fatality rates to be high, there has to be enough crashes where the effective impact velocity is higher than 80 to $100 \mathrm{~km} / \mathrm{h}$ for belted and airbag-protected occupants. The fact that vehicle fatality rates are low in New York means that average speeds would be low there. The same explanation should hold for the eight cities that have vehicle fatality rates of 0 per 100000 population (Table I), they also have rates of zero for pedestrians. The fact that a city can have high fatality rates for vehicles (indicating higher average vehicle speeds) and low rates for pedestrians implies that these cities would have low pedestrian exposure and hence low rates for them.

\section{Crash rates and city structure}

In the absence of detailed traffic modal share and speed and crash information, we can only have informed guesses on what is happening in all these cities. The international data show that per capita income is not the only determining criterion for fatality rates, as the rates can vary by a factor of three among the richest nations. To control for different vehicle design and road design

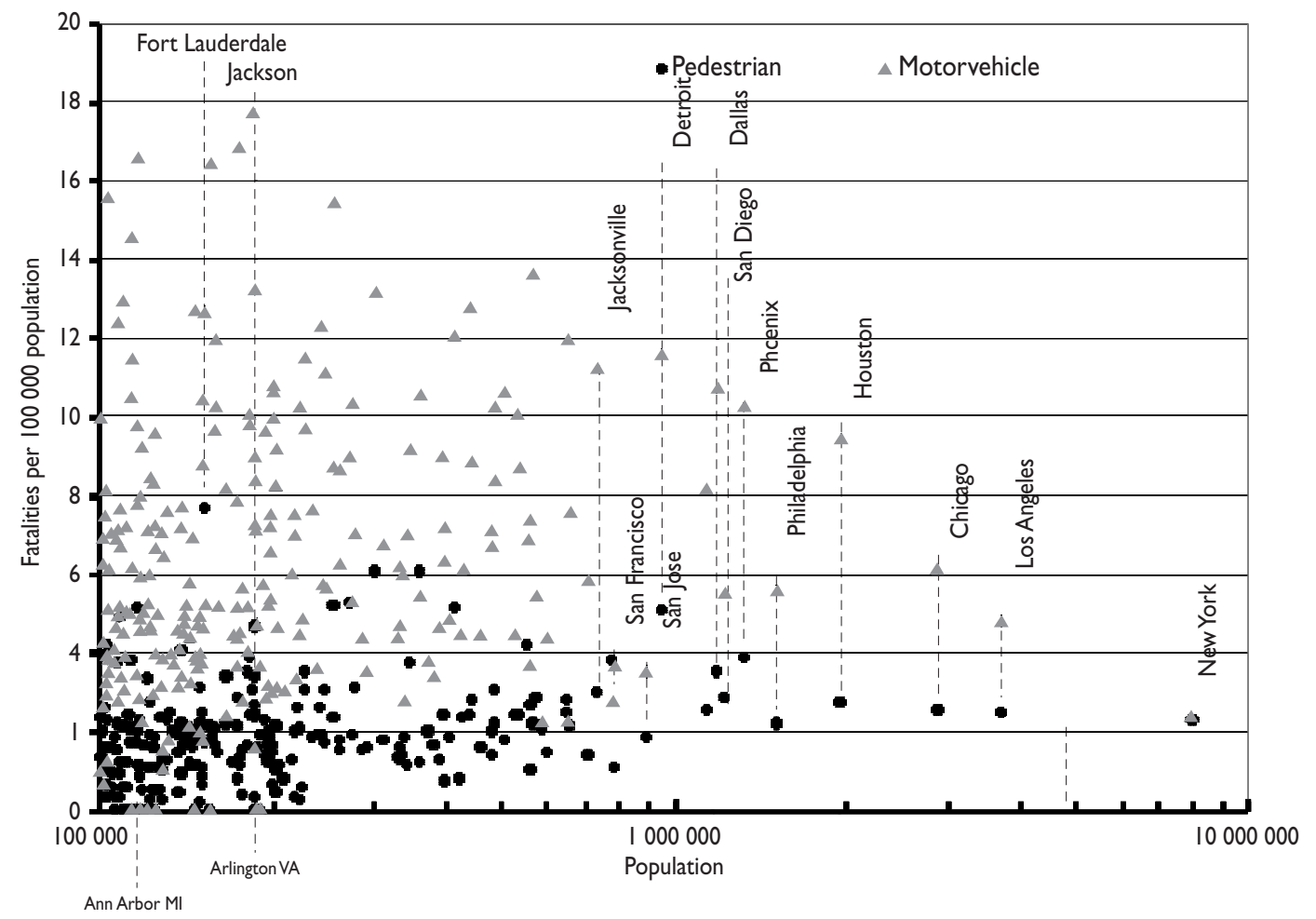

Figure 2. Pedestrian and motor vehicle fatality rates per 100000 population in 245 Cities (population $>100000$ Persons) in the United States of America (Source: Reference 7) 
Table I

TEN CITIES WITH LOWEST PEDESTRIAN FATALITY RATES IN USA

\begin{tabular}{lccc} 
City & Population & $\begin{array}{c}\text { Pedestrian } \\
\text { fatality per } \\
100000 \text { pop }\end{array}$ & $\begin{array}{c}\text { Motor vehicle } \\
\text { fatality per } \\
100000 \text { pop }\end{array}$ \\
Ann Arbor, MI & 114024 & 0 & 0 \\
\hline Spring Valley CDP, NV & 117390 & 0 & 0 \\
\hline Elizabeth, NJ & 120568 & 0 & 0 \\
\hline East Los Angeles CDP,CA & 124283 & 0 & \\
\hline Metairie CDP, LA & 146136 & 0 & 0 \\
\hline Sunrise Manor CDP, NV & $156 I 20$ & 0 & 0 \\
\hline Paradise CDP, NV & 186070 & 0 & 0 \\
\hline Arlington CDP,VA & 189453 & 0 & 0 \\
\hline Bellevue,WA & 109569 & 0 & 3.04 \\
\hline Manchester, NH & 107006 & 0 & 4.98
\end{tabular}

Source: Reference 7

Table II

ThIRTEEN CITIES IN USA (POPULATION < 200 000) WITH PEDESTRIAN FATALITY RATES $>$ THREE PER I00 000 POPULATION

\begin{tabular}{lccc} 
City & Population & $\begin{array}{c}\text { Pedestrian } \\
\text { fatality per } \\
100000 \text { pop }\end{array}$ & $\begin{array}{c}\text { Motor vehicle } \\
\text { fatality per } \\
100000 \text { pop }\end{array}$ \\
Gary, IN & 102746 & 4.22 & 15.57 \\
\hline Waterbury, CT & 107271 & 3.73 & 12.43 \\
\hline Beaumont, TX & 113866 & 3.81 & 14.63 \\
\hline Columbia, SC & 116278 & 5.16 & 16.63 \\
\hline Fayetteville, NC & 121015 & 3.31 & 7.16 \\
\hline Pomona, CA & 149473 & 3.12 & 4.91 \\
\hline Fort Lauderdale, FL & 152,397 & 7.66 & 12.68 \\
\hline Dayton, OH & 166,179 & 3.41 & 8.22 \\
\hline Reno, NV & 180480 & 3.51 & 4.06 \\
\hline Salt Lake, UT & 181743 & 3.85 & 10.09 \\
\hline Jackson, MS & 184256 & 3.08 & 17.72 \\
\hline San Bernardino, CA & 185401 & 3.42 & 8.99 \\
\hline Orlando, FL & 185951 & 4.66 & 13.27
\end{tabular}

Source: Reference 7

policies, we have compared rates for cities within the USA. These data show that within the same state:

- Cities have different crash rates -San Diego and San Jose in California.

- Have different patterns -San Francisco has a higher rate for pedestrians and Los Angeles has a higher rate for vehicles.
- One city can have the a zero rate of fatalities (East Los Angeles CDP) and another city in the same state with a similar population can have one of the highest rates (San Bernardino, CA).

We also know that improvements in the crashworthiness of vehicles, use of seatbelts and airbags and other safety devices can reduce fatality rates by 30 to $70 \%$ and alcohol control by about 30 to $40 \%,{ }^{1}$ and that enhancement in road and infrastructure facilities can lead to an increase in fatalities. ${ }^{8}$ But the differences in rates across cities in USA and internationally show a difference by factors of three or more. This seems to suggest that city structure, modal share split and exposure of motorists and pedestrians may have a greater role in determining fatality rates than vehicle and road design alone.

Therefore, the results from the analysis of city data seem to suggest very strongly that cities with high motor vehicle fatality rates must be those where exposure and speeds of motorists are high, and pedestrian fatality rates can be low if pedestrian exposure is low. Within the USA, where incomes, availability of technology, knowledge, and road design and vehicle specifications can be similar across cities, these differences in speeds and exposure are probably accounted for by the structure of cities.

At the international level, cities that have modernised and expanded in the past few decades are those in the per-capita income range of USD 1 000-10 000, and these are the cities with very high fatality rates (Durban, Johannesburg, Tehran, etc.). Typically, these cities have built wide avenues and high speed corridors within the city. In India, Delhi has a high fatality rate, and Mumbai and Kolkata, low rates. Here also, Delhi has much faster vehicle traffic than Mumbai and Kolkata and a lower density of through-traffic streets.

With the same proportion of land devoted to road space, we can have large blocks with fewer arterial roads or smaller blocks with a larger number of arterial streets. In the former type of cities the avenues would be wider than the latter type of cities. If the arterial streets are wide, it encourages high speeds during off-peak hours, resulting in high pedestrian and bicycle crash rates. High pedestrian and bicycle fatality rates discourage use of non-motorised modes and of public transport.

If it is not easy for city residents to walk, bicycle or use public transport, then they will prefer to use private modes of transport. When a majority of commuters are dependent on motor vehicle use for their essential needs, the system creates a political demand for greater provision of motor vehicle facilities and road space. This in turn can make it difficult for the political system to be harsh on drivers in terms of speed enforcement and 
controlling drinking and driving. In this situation, not only do people tend to use motor vehicles for short trips, but also demand facilities that reduce trip time for long trips. These conditions are just right for increasing the exposure of people on roads with less than optimal conditions for ensuring road safety.

\section{Conclusions}

Most of the megacities in the world are already located in LMICs and many more cities in these countries will grow to populations of ten million or more in the next few decades. All these cities are faced with serious problems of inadequate mobility and access, vehicular pollution, road traffic crashes and crime on their streets. Increasing use of cars and motorised two-wheelers add to these problems and this trend does not seem to be abating anywhere. Many recent reports suggest that improvements in public transport and promotion of non-motorised modes of transport can help substantially in alleviating some of these problems. ${ }^{9-11}$ However, LMIC cities have very mixed land use patterns, with a very large proportion of all trips being walk or bicycle trips; of the motorised trips, more than $50 \%$ are by public transport or shared para-transit modes; compared to HICs, trips per capita per day are lower and a significant proportion of trips can be less than $5 \mathrm{~km}$ in length; costs of motorised travel are high compared to average incomes.

Deaths and injuries due to road traffic crashes are also a serious problem in LMICs. According to one estimate, the losses due to accidents in LMICs may be comparable to those due to pollution. ${ }^{12}$ Such issues make transport planning in LMIC cities a very complex affair. HMIC cities have not experienced the existence of such a large proportion of motorised two-wheelers, paratransit vehicles and non-motorised modes of transport sharing road space with cars and buses.

Walking and bicycling are the only clean modes of transport available. The use of these modes reduces as incomes rise and cities become unfriendly to these modes when they design roads with only motor vehicles as a priority. The main reason for this is that walking is not safe. The high risk of injuries and fatalities in urban areas to pedestrians, bicyclists and commuters in access trips have been documented from all over the world. In New South Wales, Australia, the greatest risk to schoolchildren from bus-related injuries was found to be as pedestrians after alighting from a bus ${ }^{13}$ in Mexico City, $57 \%$ of deaths from traffic crashes involve pedestrians; ${ }^{14}$ injury to pedestrians was the most frequent cause of multiple trauma (54\%) among children 0 to 16 years in a large Spanish urban area, ${ }^{15}$ in
California, a motor vehicle versus pedestrian accident study reported that these accidents are common and the high mortality rate among the elderly indicated the need for more aggressive and effective prevention efforts; ${ }^{16}$ a study from Canada showed that children's exposure to traffic (number of streets crossed) and injury rates were positively correlated; ${ }^{17}$ in Kumasi, Ghana, the most common mechanisms of injury ( $40.0 \%$ ) to children were pedestrian knock-downs; ${ }^{18}$ a study of older people's lives in the inner city of Sydney, Australia showed that the environmental hazards, such as pedestrian safety and traffic management, affect the whole population and require interventions at the government level; ${ }^{19}$ a study from Seattle shows that $66 \%$ of fatal injuries occurred on city or residential streets, $29 \%$ occurred on major thoroughfares, and a single urban highway accounted for $12 \%$ of pedestrian fatalities and represented a particularly hazardous traffic environment. ${ }^{20}$

\section{Issues for sustainable transport}

- In the next ten years purely technological solutions in design of vehicles and their engines can only lead to a small reduction in injury and fatality rates.

- Policing and traffic management techniques are not likely to reduce traffic fatality rates by more than $50 \%$ to $75 \%$, though we see a difference of fatality rates by factors of 4 to10 among cities.

Therefore, it seems that if we have to promote walking, bicycling and public transport use we will have to make traffic safety a priority along with city structure designs that incorporate the following:

1. Street design ensuring safety of non-motorised modes.

2. Vehicle speed control by street design and ultimately ITS control on vehicles.

3. Denser layout of through-traffic streets with narrower cross sections.

4. Smaller size of residential neighbourhoods.

\section{References}

I. Peden M, Scurfield R, Sleet D, Mohan D, Hyder AA, Jarawan E, et al. World report on road traffic injury prevention. Geneva:World Health Organization, 2004.

2. Mohan D. Road Transport and the Environment in Less Industrialized Countries. Journal of International Association of Traffic and Safety Sciences 1992;15(2):55-68.

3. Mohan D, Tiwari G, Khayesi M, Nafukho FM. Road Traffic Injury

Prevention Training Manual. Geneva:World Health Organization, 2006. 
4. Koornstra M, Lynam D, Nilsson G, Noordzij P, Pettersson H-E, Wegman F, Wouters P. SUNflower:A comparative study of the development of road safety in Sweden, the United Kingdom, and the Netherlands. Leidschendam: SWOV, 2002.

5. Lai CH, Huang WS, Chang KK, Jeng MC, Doong JL. Using data linkage to generate 30-day crash-fatality adjustment factors for Taiwan. Accid Anal Prev 2006;38(4):696-702.

6. Kopits E, Cropper M. Traffic fatalities and economic growth. Accid Anal Prev 2005;37(I):169-I78.

7. Shankar U. Pedestrian Roadway Fatalities. Washington, DC: National Center for Statistics and Analysis, National Highway Traffic Safety Administration, 2003. Report No. DOT HS 809456.

8. Noland RB.Traffic fatalities and injuries: the effect of changes in infrastructure and other trends. Accid Anal Prev 2003;35(4):599-612. 9. Mohan D, Tiwari G, Saraf R, Kale S, Deshmukh SG, Wadhwa S, et al. Delhi on the move: Future traffic management scenarios. Delhi: Transportation Research and Injury Prevention Programme/Indian Institute of Technology, 1996.

I0.Wu Y, Li X. Targeting Sustainable Development for Urban Transport. Beijing: CICED, 1999

II. European Commission. European transport policy for 2010: time to decide. Luxembourg: Office for Official Publications of the European Communities, 200I.
12.Vasconcellos EA. Urban Development and Traffic Accidents in Brazil. Accid Anal Prev 1999;31 (4):319-328.

13. Cass DT, Ross F, Lam L. School Bus Related Deaths And Injuries In New South Wales. Med J Austr 1997;166(2): 107-108.

14. Hijar MC, Kraus JF, TovarV, Carrillo C. Analysis of Fatal Pedestrian Injuries in Mexico City, 1994-1997. Injury 200I;32(4):279-284.

I5. Sala D, Fernández E, Morant A, Gasco J, Barrios C. Epidemiologic Aspects of Pediatric Multiple Trauma in a Spanish Urban Population.J Pediatr Surg 2000;35(I0): 1478-I48I.

16. Peng RY, Bongard FS. Pedestrian Versus Motor Vehicle Accidents:An Analysis of 5,000 Patients. J Am Coll Surg 1999;189(4):343-348.

17. Macpherson A, Roberts I, Pless IB. Children's Exposure to Traffic and Pedestrian Injuries. Am J Public Health 1998;88(I2):I840-1843.

18. Abantanga FA, Mock CN. Childhood Injuries in an Urban Area of Ghana a Hospital-Based Study of 677 Cases. Pediatr Surg Int 1998; |3(7):5|5-5|8.

19. Russell C, Hill B, Basser M. Older People's Lives in the Inner City: Hazardous or Rewarding? Austr N Z J Public Health 1998;22(I):98-106. 20. Harruff RC,Avery A,Alter-Pandya AS.Analysis of circumstances and injuries in 217 pedestrian traffic fatalities. Accid Anal Prev 1998;30(I): I I-20. 
Appendix I

\begin{tabular}{llll} 
Code & \multicolumn{1}{c}{ City } & Code & \multicolumn{1}{c}{ City } \\
ACC & Accra & HOU & Houston \\
ADD & Addis Ababa & IXC & Chandigarh \\
\hline ADL & Adelaide & JNB & Johannesburg \\
\hline AMD & Ahmedabad & KIX & Osaka \\
\hline BER & Berlin & KUL & Kuala Lumpur \\
\hline BKK & Bangkok & LAX & Los Angeles \\
\hline BFN & Bloemfontein & LON & London \\
\hline BNE & Brisbane & MAA & Chennai \\
\hline BOG & Bogota & MEL & Melbourne \\
\hline BOM & Mumbai & MEX & Mexico City \\
\hline BOS & Boston & MNL & Manila \\
\hline BRU & Brussels & MPM & Maputo \\
\hline CCU & Kolkata & MUC & Munich \\
\hline CGK & Jakarta & NBO & Nairobi \\
\hline CGP & Chittagong & NYC & New York City \\
\hline CHI & Chicago & PAR & Paris \\
\hline CLO & Cali & PEK & Beijing \\
\hline CPT & Cape Town & PHX & Phoenix \\
\hline DAC & Dhaka & PLZ & Port Elizabeth \\
\hline DEL & Delhi & PNQ & Pune \\
\hline DEN & Denver & PRY & Pretoria \\
\hline DKR & Dakar & RUH & Riyadh \\
\hline DTT & Detroit & SEL & Seoul \\
\hline DUR & Durban & SIN & Tingapore \\
\hline DXB & Dubai & TYO \\
\hline GRU & Sao Paulo & VIE & Tokyo \\
\hline HIW & Honolulu & WAS & Vienna \\
\hline HKG & Hong Kong & & \\
\hline & & & \\
\hline & & & \\
\hline
\end{tabular}

